\title{
La documentación notarial de las "ultimidades" para la historia social y cultural rural de la Europa moderna*
}

\author{
The notarial documentation of the "ultimities" for the social and cultural history of modern Europe \\ María Soledad Gómez Navarro \\ Universidad de Córdoba, España \\ hilgonas@uco.es
}

\section{Resumen:}

Este texto pretende mostrar las potencialidades y utilidades -también las dificultades- de la documentación notarial más específica e idónea para estudiar las actitudes ante la muerte en la Europa rural del Antiguo Régimen; incide, por tanto, en escrituras de última voluntad (testamentos, en sus varios y diversos tipos; memoriales, memorias testamentarias, codicilos), escrituras sueltas de donaciones y fundaciones, y de liquidación y distribución de bienes por el óbito (partijas, particiones e inventarios post mortem). No obstante, y para enmarcar ese apartado, que es el central y fundamental de esta aportación, dos más lo acompañan, pues se reflexionará también sobre el aprovechamiento de los instrumentos escribaniles para la Historia económica, social y cultural, y sobre una de las historiografías más beneficiadas al respecto, como ha sido la relativa a los comportamientos colectivos ante la muerte en la España moderna.

Palabras claVe: Documentación notarial, Muerte, Medio rural, España, Europa, Antiguo Régimen.

\section{Abstract:}

This text aims to show the potentialities and utilities -also the difficulties- of the most specific and suitable notarial documentation to study attitudes towards death in rural Europe of the Old Regime; it affects, therefore, in writings of last will (testaments in their various and diverse types; memorials, testamentary memories, codicils), loose deeds of donations and foundations, and of liquidation and distribution of goods by death (particles, partitions and inventories post mortem). However, and to frame that section, which is the central and fundamental part of this contribution, two more accompany it, since it will also reflect on the use of the notarial instruments for economic, social and cultural history, as well as on one of the most benefited historiographies in this regard, as has been related to collective behaviors in the face of death in modern Spain.

KEYWORDS: Notarial documentation, Death, Rural environment, Spain, Europe, Old Regime.

Como reza el resumen de esta contribución, el objetivo fundamental de la misma es presentar la documentación notarial más específica e idónea para la indagación y conocimiento de las actitudes colectivas ante la muerte en la Europa católica rural del Antiguo Régimen. Estas fuentes son escrituras de última voluntad -testamentos, en sus varios y diversos tipos; codicilos, memoriales y memorias testamentarias-, escrituras propias y sueltas de donaciones y fundaciones pro anima, y escrituras de liquidación y distribución de bienes con motivo de la muerte -es decir, partijas, particiones e inventarios post mortem-. También se dedicará breve atención a la documentación notarial en general, sobre todo por su utilidad para la historia económica, social y cultural, así como a los mimbres básicos de una de las historiografías más frecuentadas al respecto, como ha sido la tanatológica -en concreto la hispánica-, completando así los tres apartados que lo constituyen. 


\section{1.- UNA DOCUMENTACIÓN MUY VERSÁTIL PARA LA HISTORIA RURAL: DE LO ECONÓMICO A LO CULTURAL}

Comencemos con una interrogante: ¿Cómo podemos conocer a la gente normal y corriente del medio rural, la gente poco importante como dice José Andrés-Gallego, que es, por otra parte, la parte más masiva y mayoritaria de la sociedad europea del Antiguo Régimen? Para ello tenemos una documentación muy útil, por la variedad de información que contiene y porque muestra también al medio rural. Una documentación que permite despejar ciertas incógnitas siempre interesantes, como la representatividad social de la fuente, la especialización notarial y el clientelismo escribanil, elementos estos últimos, por lo general, ausentes en las investigaciones que han tenido al notario como protagonista, salvo honrosas excepciones (Extremera Extremera, 2001, 2009. Mendoza García, 2007a, 2007b. Domínguez Guerrero, 2019. Calleja Puerta, Domínguez-Guerrero, 2018). Y, sobre todo, una documentación que aporta y refleja el pulso de la sociedad "real" en su discurrir cotidiano. Obviamente me refiero a la huella notarial de los legajos escribaniles; los únicos, además, que permiten dar contenido a lo diario y primario, es decir, conocer y explicar de qué viven, dónde viven y cómo viven los individuos, aunque siempre enfatizando la dimensión social de lo cultural (Franco Rubio, 2018).

Para valorar el alcance de la documentación notarial comienzo con una cita ya clásica:

Asomarse, pues, a un protocolo cualquiera de aquellos tiempos es como otear desde un altozano todo el panorama de la vida española, departir con sus personajes ora famosos, ora humildes, que, confiados en el secreto profesional, nos descubrirán y confesarán sin empacho sus necesidades, sus trampas, lacras, ambiciones y lacerías, y a las veces también ¿por qué no?, hermosas virtudes, la liberalidad, la hidalguía, el cariño y el amor. Todos los sentimientos y afectos del alma humana, desde sus grandezas hasta sus miserias, desde la opulencia hasta la pobreza, desde el amor que perdura hasta el odio que persigue, desde la cuna hasta la sepultura, quedarán prendidos y presos en estos protocolos con los rasgos de la péñola escribanil... Por todo ello, los infolios y mamotretos de los archivos escribaniles... me han parecido siempre como basas macizas y sillares superpuestos de una ingente y colosal muralla, que atajase y represase el caudal abundantísimo y turbulento de la vida privada familiar, social, artística y literaria de los pasados siglos.

Aquí, en estas muy conocidas palabras, ya estaba todo (González de Amezúa y Mayo, 1951, pp. 289-290). Por eso lo de "inexcusable" e inevitable con que me he referido a la huella notarial (Gómez Navarro, 2003), porque es imposible escribir historia, desde luego Historia Moderna, pero aun también en sus etapas previa y posterior, y en cualquiera de sus distintas parcelas, sin recurrir a tal fuente documental.

En efecto, en ese expresivo y sugerente texto están contenidos todos los temas que luego la investigación posterior en historia económica, social o cultural se ha encargado de ir desvelando y aquilatando. Sin duda que para la reconstrucción de una sociedad como la del Antiguo Régimen, tan acostumbrada a acudir al notario para resolver o plantear cualquier asunto de su vida cotidiana, por baladí que este fuera u hoy lo pueda parecer, es indispensable la paciente consulta de documentación notarial (Eiras Roel, 1985, pp. 27-28; Laffont, 1991, 1992; Poisson, 1976, pp. 996-997; Vogler, 1979). Veamos, pues, su origen, sus utilidades, sus luces y sus sombras, elaboración que compendia muchas y específicas lecturas al efecto (Gómez Navarro, 1996, pp. 2-7).

Como es sobradamente conocido, la prehistoria de la utilización de las fuentes notariales estuvo marcada por el carácter esporádico y concreto, es decir, por la singularidad de lo que en ellas se iba a buscar. Sin embargo, un segundo paso, en el que se sitúa la mayor parte de la última generación de modernistas que las ha empleado y obviamente yo misma, viene representado por el estudio seriado, sistemático y cuantitativo de un buen número de escrituras notariales de un mismo tipo e idéntica naturaleza, cuya regularidad y siempre constante ordenación y presentación de su información, facilitan su informatización y serialización. Llegar a este punto supone reconocer el trabajo individualizado de algún precursor -Roland Mousnier, por ejemplo-, y el esfuerzo historiográfico colectivo de otros muchos, que han descrito una evolución dinámica y ritmada, cuando menos, por el impacto de tres momentos importantes, a saber: iniciación, despegue o take-off, y consagración. 
El primero se vincula a la llamada lanzada por Ernest Labrousse a los historiadores reunidos en Roma en 1955 con motivo del X Congreso Internacional de Ciencias Históricas, con el fin de emplear las fuentes notariales en un nuevo proyecto de investigación de la historia social de los tiempos modernos.

En el segundo son distinguibles, a su vez, dos momentos distintos: uno, aproximadamente hacia 1959, representado por la aplicación a esa parcela histórica de algunos discípulos de Labrousse -Daumard, Furet, Dupeux- y Mousnier -Durand, Fayard, Le Flem-, cuyos trabajos y artículos sobre ese tema son publicados en Annales y otras revistas francesas. Y otro, sin duda el más importante, desde 1960, año de la publicación de la importante tesis ruralista de Pierre Goubert, que fue seguida de otras monografías regionales de Historia rural -entre otras, las de Baehrel, Vilar, Poitrineau, Le Roy Ladurie, Lebrun, Jacquart, Croix, etc.-, de historia urbana -Bennassar, Deyon, Garden...-, o sobre grupos sociales cualificados, como fueron los trabajos de Durand y Chaussinand-Nogaret, que recurrieron ampliamente a las huellas notariales.

Por último, su consagración pareció llegar con la celebración de los primeros congresos internacionales dedicados específicamente al tema -Estrasburgo, 1979; Santiago de Compostela, 1982- y la comprobación de que sus Actas asumían la incorporación de la Historia de las Mentalidades, en gran medida desarrollada por la tercera generación de Annales y su asalto a lo que sus integrantes llamaron el tercer nivel -esto es, la cuantificación en la medición del actitudes, comportamientos y respuestas-, y cuyos temas de investigación se abordaban en gran parte desde la exploración de este tipo de fuentes, como sección histórica de pleno derecho.

La recepción en España de toda esta renovación historiográfica y metodológica que se estaba gestando en Francia debe mucho a las inquietudes de la "escuela gallega", que, encabezada por Antonio Eiras Roel, demostró su interés por no quedarse atrás a partir de los años setenta del pasado siglo. Aunque con cierto retraso respecto al proceso que acabo de exponer, es claro que el estreno de esos planteamientos basados en el aprovechamiento masivo y sistemático de la documentación notarial y en su tratamiento seriado y cuantitativo tuvo lugar en Santiago de Compostela, en 1975, con las I Jornadas de Metodología Aplicada de las Ciencias Históricas, alcanzando su "mayoría de edad" con la publicación en 1984 de las Actas del II Coloquio de Metodología Histórica Aplicada. La Documentación Notarial y la Historia, realizado en la misma ciudad dos años antes y cuyos contenidos respondían ya bastante bien al grado de madurez que empezábamos a lograr en muchos aspectos (Eiras Roel, 1980, pp. 25-27).

En relación con ese descubrimiento y sedimentación de la documentación notarial se deduce también la experiencia lograda sobre las posibilidades que brinda su rico caudal informativo, el variado aprovechamiento que permite, sin duda ya no de forma desordenada o puntual, sino como parte de un proyecto de investigación seriado e integrado, y los beneficios que resultan de su manipulación para hormar resultados o enriquecer los ya existentes en distintas parcelas del saber histórico.

En sus arrendamientos, dotes, inventarios, fianzas, censos, obligaciones, poderes, testamentos, fundaciones, donaciones, etc., se hallan los secretos del conocimiento sobre condiciones de propiedad y explotación de la riqueza rústica y urbana, constitución y gestión de familias y patrimonios, endeudamiento, relaciones sociales, cultura material y libresca, actitudes, comportamientos y valores morales, y tantas otras temáticas e inquietudes; y es, por tanto, indudable que, como decíamos anteriormente, hoy nadie puede hacer Historia económica, política, social, religiosa o cultural sin consultar aquellas y otras escrituras notariales que, por razones de espacio, tengo que orillar (Eiras Roel, 1981). Baste, como muestra de esas indicadas enormes utilidades las escrituras de última voluntad -en concreto, el testamento- para diversos ámbitos de la historia económica y social, al pronunciarse sobre:

Cuestiones personales: declaraciones sobre presentación de méritos, justificación de algún pormenor en relación con el estado civil, peripecias y avatares.

Asuntos familiares: confesiones referentes a la prole -reconocimiento de tener hijos naturales, sentimiento de gratitud o rencor hacia ellos, preocupación por su educación, o por la impresión de ciertos valores morales-; a los propios otorgantes -contingencias sobre la filiación del declarante, agradecimiento entre esposos o desavenencias entre cónyuges-; e incluso al linaje, caso en que pueden adoptar diversas formas, 
como conciencia de grupo y prestigio -hidalguía-, conservación del patrimonio, sentimiento de solidaridad, explicitación de las relaciones mantenidas con distintos miembros de la familia, y sentido de ayuda, colaboración y vigilancia por la integridad de los bienes familiares.

Aspectos de índole económica: testimonios sobre pobreza, propiedad de bienes, o pérdidas y/o situación de bonanza.

Aspectos de índole social: en general, ensanchando el estrecho círculo de las comentadas relaciones estrictamente privadas y situando al testador en su vinculación con los demás, en su disposición, mediante los legados profanos, en favor de conocidos, amigos, particulares y subordinados con quienes mantiene distintos lazos de dependencia, laboral, material o de cualquier otra índole. En suma, todos esos aspectos hacen del testamento documento extraordinariamente apto para esos y otros fines (Gómez Navarro, 1996, pp. 29-32).

Esas son sus principales "luces”. La cantidad de escrituras de arrendamientos -rústicos y urbanos-, poderes, censos y obligaciones de pagos, o dotes y testamentos, están indicando la aplastante presencia de la vinculación y la amortización como estructura básica de la propiedad raíz que hace del sistema indirecto de explotación pieza fundamental del engranaje económico y social. También la necesidad de constante intermediación para todo tipo de actos jurídicos en una sociedad masiva y mayoritariamente iletrada y dinámica; el peso del endeudamiento popular, y las relaciones, afectivas o no, familiares, personales, sociales y religiosas.

Las actas notariales tienen sus sombras, como, por lo demás, las tiene toda fuente histórica. Supuesto ya que hoy nadie duda de la necesidad de su consulta, y de que las escrituras notariales, aun con el escribano como intermediario, "son el reflejo real de la vida social, de las relaciones económicas y sociales entre los individuos y entre los grupos” (Eiras Roel, 1981, p. 9), tras encajar esa euforia de los primeros años, motivada por el descubrimiento de esta fuente y su aprovechamiento seriado, se inicia en la historiografía hispánica, a partir del comienzo de los años ochenta del pasado siglo (Eiras Roel, 1984, p. 30), otra etapa de acercamiento a la documentación notarial. Esta etapa estuvo caracterizada por un nuevo modo de acercamiento, más cauto o prevenido si se quiere, pero también más ajustado a lo que se iba comprobando que de ella se podía esperar; una etapa impulsada además por el deseo de proceder a su depuración. En realidad, se asumían así en la documentación notarial, huellas de gran complejidad y elaboración que por su naturaleza y soportes son constituyentes de la historia serial o "historia-problema" (Cardoso y Pérez Brignoli, 1986, pp. 20, 31, 34), la problemática metodológica de la autenticidad y la fiabilidad de las fuentes y de sus informantes (Topolski, 1982, pp. 333-349). Quienes acometían esta nueva andadura con el bagaje de la experiencia acumulada, propia pero sobre todo ajena (Meyer, 1979, pp. 35, 43-44), eran conscientes de que ya se había desvanecido uno de los sueños a los que invitaba esta fuente, a saber, una excesiva confianza en que reflejaba todos los niveles económicos y sociales de la población. Se empezó a comprobar que esa documentación entregaba las vivencias y los testimonios de "solo una parte de la sociedad", e incluso de una parte cualificada de la misma. Dicho de otra forma, eran todos los que estaban - por eso es suficientemente representativa desde el punto de vista social-, pero no estaban todos los que eran los "hombres sin historia", parafraseando el viejo deseo de Lucien Febvre. Me refiero a la convicción de impulsar la crítica o depuración de la fuente. Aparecía así el filtro entre el sujeto y el objeto, el saludable sentido de la desconfianza que debe guiar siempre al historiador cuando se enfrenta al diálogo con el pasado y la manipulación de sus huellas.

Hasta ahora, la crítica de las fuentes notariales, en general, y de las actas de última voluntad en particular, y sobre todo del testamento como documento pionero en la serialización de su información, se ha encauzado fuera y dentro de España, aunque enfatizo este último ámbito, básicamente en tres direcciones, cuya ordenación, según la atención que han despertado y el grado de preocupación que han suscitado, sería la siguiente (Eiras Roel, 1984, pp. 27-29):

Representatividad: de qué universo hablamos. Este es un número que tampoco permanece estable, sino que cambia según el tiempo y, sobre todo, según el tipo de escritura notarial manejada. Es el problema de la accesibilidad a la fuente por los distintos agregados sociales y de la representación diferencial que estos 
describen según también distintas clases de actas notariales (Eiras Roel, 1985, p. 17; López López, 1988, p. 99; Marcos Martín, 1989, pp. 55-56).

Autenticidad o veracidad: remite al filtro del formulario notarial, y al papel del escribano.

Suficiencia (y esta, en un triple sentido): refiere al problema de los métodos, a cómo buscar los más idóneos para la selección de una documentación que casi siempre resulta ingente (Eiras Roel, 1980, p. 23; Pérez García, 1975, pp. 293-294; Moreno Trujillo, pp. 9-14). A su vez, remite a la exclusiva utilización de esos métodos para alcanzar con las máximas garantías la explicación y el conocimiento más completo sobre la realidad que se estudie. Finalmente, al problema de los frecuentes silencios de la fuente sobre determinados aspectos, a saber, ausencia total de alusiones a ciertas fases del ritual funerario, o que se disponga o no la explicitación de su contenido en manos de terceros o albaceas, ya sean familiares o no, con lo que, si no se cuenta con la correspondiente escritura de división y adjudicación de bienes post mortem, evidentemente el ritual funerario completo puede quedar ignoto.

Pese a estas objeciones, la fuente notarial serial ofrece una riqueza indudable, $y$, en general, un más que aceptable nivel de representatividad, que permite comprobar y valorar el grado de apropiación social de los modelos culturales dominantes (Gómez Navarro, 1998b, pp. 31-52; 2003, pp. 44-69; Laffont, 1991; Vovelle, 1984, p. 25). En ese camino, una de las temáticas más desarrolladas ha sido, en lo cultural, la del estudio de los comportamientos ante el destino final de la vida. Veamos, pues, aunque sea someramente, sus principales mimbres, fijándonos sobre todo en los hispánicos.

\section{2.- UNA HISTORIOGRAFÍA CON DOCUMENTACIÓN NOTARIAL ESPECIALMENTE EXITOSA: LAS aCtitudes ante la muerte en la España del Antiguo Régimen}

\section{La muerte tarda en entrar en el ámbito de la Historia}

La muerte está de moda desde el punto de vista científico, quizás porque sea de esos tournant que siempre vuelve coincidiendo con crisis general de valores como la que parece vivirse desde fines del pasado siglo. Ello ha producido toda una floración de trabajos -tanto más llamativa o sorprendente cuanto hace tiempo se constata la denunciada actitud de la industrializada sociedad occidental por su ocultamiento, olvido o escamoteo (Gorer, 1955)-, y de enfoques muy diversos y atribución geográfica casi diferencial: en América, sociológicos; en Francia o España, históricos; en Alemania, filosóficos y hasta religiosos. La muerte sigue siendo, por tanto, preocupación universal como avalan estudios antropológicos, etnográficos, sociológicos, literarios, médicos, psicológicos y parapsicológicos, teológicos, y, por supuesto, filosóficos, disciplina esta última que, como es sabido, ha hecho de la muerte "el centro arquimédico de cualquier concepción del mundo, la razón o sinrazón de la vida, la síntesis superadora de todos los valores" (Pérez del Río, 1984, p. 78). Empero, la presencia de la muerte entre las preocupaciones del historiador es relativamente reciente, aunque ya la lapidaria proposición de Febvre de que no había historia de la muerte (1953 [1986], pp. 221-238; Burguière, 1986, p. 480), ha quedado obsoleta. Con la perspectiva que da el paso del tiempo, hoy sabemos que la historia de la muerte se ha beneficiado directamente del nacimiento y desarrollo de dos componentes esenciales de la denominada Nueva Historia -lo vital y lo social-, al surgir del encuentro entre la demografía y las mentalidades.

En efecto, lo que empezó como una preocupación primordial de la demografía histórica -factores de la muerte física, peso de la mortalidad, lucha social por sacudir el yugo del ciclo demográfico antiguo (Meuvret, Goubert, Henry, Fourastié, Flinn, entre otros)- y de la historia social -analisis regionales de los comportamientos sociales ante la muerte, aunque a mitad de camino ya entre lo demográfico y lo "gestual", porque atendían también a las manifestaciones externas de la mentalidad colectiva (Lebrun sobre Anjou y Croix sobre Bretagne)-, terminó por convertirse en interés preferente de la historia de las mentalidades e historia cultural, al interesarse esta por el examen de las formas de pensamiento y modos de expresión que, en conexión con lo social y lo material, manifiesta la colectividad ante los grandes 
radicales de la vida humana, como es la muerte, singular observatorio y espejo a través del cual explorar y analizar ideas, sentimientos, actitudes y comportamientos, "reflejos inconscientes de las sensibilidades, expresión de lo imaginario" (Vovelle, 1985, p. 192), hasta llegar “a lo más secreto y a lo más profundo del hombre" (Carbonnell, 1986, pp. 141-142).

De esta forma empiezan a publicarse al filo de los años setenta del pasado siglo los primeros trabajos sobre las actitudes ante la muerte -Ariès, solitario pionero durante muchos años en esas lides; Vovelle; Chaunu; Favre; Cruysse; Lorcin; Chiffoleau; Le Goff..., y tantos otros-, resultados ante los que, con razón, Vovelle afirmaría al principio de los ochenta que la historia de la muerte no había hecho más que comenzar, y balance hoy claramente superado y muy maduro, al menos en España.

Ese creciente interés por la muerte y sobre todo la madurez de sus conocimientos en la historia de las mentalidades probablemente obedezca a que, en la compleja red de sus inquietudes -vida, familia, infancia, temor, amor...-, la muerte mantiene un valor ejemplar y específico, porque, radical inexcusable, en la aventura de los hombres sigue siendo un invariable ideal y esencial de observación. A juicio de Vovelle, lo que hace tan fascinante el estudio de ese universal destino es que permite "descodificar" la relación que se establece entre el hombre del Antiguo Régimen y su muerte, cuando aquel la descubre en su cotidianidad (Vovelle, 1985, pp. 100-118). Esa frontera o radical, al venir envuelta en ropaje religioso durante gran parte de la "época clásica", aparece, además, y precisamente por eso, indisolublemente unida al mundo de la transcendencia, lo que también explica la inserción de esta segunda parcela en la historia de las mentalidades (Russo, 1976, pp. cxxxiv-clxii; Viguerie, 1986, pp. 192-198). Para el historiador se trata de tomar al revés ese intercambio de miradas. En palabras otra vez del mismo Vovelle, es a partir de la muerte y de las actitudes colectivas que la acogen que "la historia quiere reencontrar a los hombres y captarlos en su reacción ante un pasaje que no tolera que se trampee" (Vovelle, 1985, p. 101). Y es que además tiene sentido estudiar la muerte en la historia; hay un sentido de la muerte en la historia, destacando, de las varias lecturas que pueden hacerse sobre la muerte desde su perspectiva histórica, las defendidas por Chaunu y Vovelle, según se enfatice lo demográfico o una realidad mucho más compleja (Gómez Navarro, 1998b, pp. 9-11).

La producción bibliográfica sobre la muerte en la Historia es prácticamente francesa por ser, con diferencia, la más abultada y sin duda la más influyente en España (lo que explica nuestra especial atención). La anglosajona, en cambio, se ha mostrado más remisa (Manners, 1981; Gittings, 1988), y la italiana, de más larga tradición ciertamente y de algún modo pionera por los trabajos de Tenenti, roza últimamente casi la antropología histórica. Por ello la tradición francesa ha propiciado toda una historiografía -trasunto, a su vez, de toda una historia de las visiones o actitudes ante la muerte-, en cuyos hitos básicos me fijo.

En la historiografía tanatológica francesa dos son las grandes líneas interpretativas que se han generado en relación al estudio de la muerte, en realidad, dos modelos historiográficos al respecto: uno representado por Michel Vovelle y sus seguidores. Otro encarnado, en casi solitario, por Philippe Ariès.

Debemos singularmente a Vovelle el descubrimiento seriado del testamento, su reconocimiento como documento-estrella, la elaboración de una metodología de trabajo y un lenguaje conceptual, y la aplicación de una interpretación (1984, p. 12). El trabajo pionero de Vovelle, el que abrió brecha y se convirtió en paradigmático, Piété baroque e déchristianisation en Provence au XVIIIe siècle (1978), tuvo prolongación en otros análisis del mismo autor que pulían, perfeccionaban y definitivamente conformaban su propia argumentación interpretativa, hasta publicar la que estimamos su obra fundamental, La mort et l'Occident. De 1300 à nos jours (1983), en la que, además de emplear como armazón teórico y conjugándola su doble concepción de verticalidad - "la muerte en tres niveles" - y horizontalidad de la muerte - muerte en la larga duración pero no inamovible y muerte como resumen de todo sistema cultural, "reflejo privilegiado de la visión del mundo" (Vovelle, 1985, p. 116), "que determina el peso específico de todas las formas de existencia que emergen del mismo" (Vovelle, 1983, p. 23) - sintetiza con maestría todos los aspectos que han constituido su posicionamiento historiográfico ante la muerte: metodológicos, documentales, y criterios diferenciales en relación al espacio, el tiempo, y los elementos sociales, económicos y culturales. 
El rastro de Vovelle fue rápidamente seguido en una doble dirección: en primer lugar, potencia el aspecto demográfico sobre el de la pura sensibilidad, aunque sin despreciar esta (Trabajo de Lebrun, Les hommes et la mort en Anjou aux 17 e et 18 e siècles, por ejemplo); en segundo término, amplía el campo documental a otro tipo de fuentes no exclusivamente notariales y centra el interés en la indagación de un núcleo urbano (obra de Chaunu, la mort La mort à Paris XVIe, XVIIe et XVIII siècles, que combina el método vovelliano con fuerte apoyo en la historia serial) o de grandes áreas regionales cuya concepción responde a la combinación de Vovelle y Lebrun (Croix, La Bretagne aux 16 et 17 siècles. La vie. La mort. La foi; Chiffoleau, La comptabilité de l'au delà. Les hommes, la mort et la religión dans la région d'Avignon à la fin du Moyen Age). Inscritas en una u otra línea -o potenciando una más que otra-, ahí están asimismo las aportaciones de Foisils, Chartier, Roche, Zerner, Berenger, Durand, Lemaitre, Thiriet, Vogler, Goujard, Bardet o Brancourt (Gómez Navarro, 1998b, pp. 161-174). Al margen de esta trayectoria, quedan las aportaciones de Ariès reunidas en una magna obra publicada en francés en 1975 y en español en 1983, El hombre ante la muerte, que recoge su modelo interpretativo de la muerte basado en la noción de "inconsciente colectivo", claramente opuesto al vovelliano. Su mérito ha sido, sin embargo, reconocido, porque no debe olvidarse que fue el primero en reivindicar el estudio de la muerte tras sus investigaciones sobre familia e infancia, e incluso algunas de sus teorías son bastante sugestivas.

La introducción en España, desde Francia, del estudio historiográfico de la muerte se produce, precoz y prontamente, a principio de los años setenta del pasado siglo, y tuvo luego muy rápida difusión. Por el volumen hasta el presente reunido y existente, la siguiente elaboración no puede ni pretende ser exhaustiva o completa, pues, aun siendo ello factible, lo que ya es difícil, esa tarea nos parecería poco operativa o útil, habida cuenta de que la actual realidad de las autopistas de la información brinda, sin cesar, fácil y casi constante acceso a cualquier novedad bibliográfica, y porque, abierto aún el tema -y sin contar trabajos en curso o inéditos, ni otras áreas disciplinares o etapas cronológicas distintas a la estrictamente histórica y Moderna-, el número de publicaciones ha crecido constante y continuamente hasta casi el presente (García Martínez, 2016). Por otro lado, eximen de tal ejercicio hitos fundamentales que forjan y forman una más que espléndida idea de conjunto (I Jornadas de Metodología Aplicada de las Ciencias Históricas, 1975; II Coloquio de Metodología Histórica Aplicada, 1984; I Encuentro sobre Religiosidad Popular, 1989, II; Mentalidad e Ideologia en el Antiguo Régimen, II Reunión Cientifica de la Asociación Española de Historia Moderna, 1993; I Congreso sobre Muerte, Religiosidad y Cultura Popular, siglos XIII-XVIII, 1994; I Simposium de Religiosidad Popular en España, 1997; o I Jornadas de Religiosidad Popular, 1998), así como magníficas síntesis de estado de la cuestión (Madariaga Orbea, 1989; Martínez Gil, 1993; Mateo Bretos, 1994; García Fernández, 1995).

Por eso, centrándonos en la época moderna y en el panorama historiográfico que ha producido ya más que suficiente en mimbres para trazar la cartografía de las actitudes hispánicas ante la muerte, exclusivamente planteo líneas, tendencias, fases, cuestiones y sobre todo puntos de atracción y/o reflexión, objetivos que, pensando especialmente en el medio rural, me parecen específicamente más útiles o interesantes; tratar de poner orden, en definitiva. Partiendo de que, en cuanto a corrientes metodológicas o historiográficas, existe bastante homogeneidad y escasa, pues, diferencia o distancia, y apostando siempre por el balance, mi criterio es el cronológico, desde mediados de los años setenta hasta 1985, y desde este hasta prácticamente el presente, siendo los últimos años precisamente los de mayor volumen, consolidación y madurez.

En este sentido, la observación de la producción historiográfico-tanatológica hispánica, marcada por la hegemonía de Andalucía, seguida -siempre en tendencias- de Cataluña, Levante, Galicia, Castilla-León, Asturias, Extremadura, Castilla-La Mancha, País Vasco, Santander y Canarias, en lo regional; la orientación norte-sur y este-oeste en la ordenación y difusión del tema; y su ya comentado enganche al banderín francés, en lo temporal, indica distanciamiento respecto a su homónima francesa, entendido este no tanto en la organización del material cuanto en ciertos aspectos formales y sobre todo estructurales. En los primeros destacan dominio de obras en colaboración; uso fuerte o casi aplastante -durante tiempo prácticamente exclusivo- de fuentes notariales, escrituras de última voluntad en concreto, y sólida implantación de la 
reproducción de un modelo que apostaba por la multiplicación de estudios puntuales restringidos a espacios muy concretos, casi siempre urbanos y raramente rurales.

En cuanto a los puntos estructurales, me refiero a la fundamental reincidencia de los autores por repetir un mismo esquema en el diseño de las cuestiones analizadas y en las motivaciones que impulsan la elaboración de los trabajos, como característica destacada en la conformación y evolución de la historiografía hispánica sobre la muerte. La mayoría de los estudios nacen, metodológica e hipotéticamente, inspirados por el deseo de aplicar el modelo vovelliano y verificar su famosa tesis de la descristianización en las actitudes colectivas ante la muerte durante la crisis finisecular del Antiguo Régimen; pese a algunos pasos, cualitativamente importantes en orden a cierta diversificación y "personalización” dados en los últimos años, poca novedad aún en cualquiera de aquellos dos extremos.

En el aspecto técnico, impera el clásico tratamiento del documento testamentario, análisis de sus cláusulas declaratorias y decisorias, limitado, por lo general, al examen de sus mensajes. En el objetivo planteado -y como he apuntado-, la interpretación francesa no se cumple casi en la totalidad de los casos examinados en el crudo sentido de su radicalidad, sino que presenta "tintes nacionales", manifestados -y en ello hay también bastante convergencia, salvo quizás el caso gaditano, y, con matices, el sevillano- en el retraso de la mutación y en su moderación. Se percibe, en efecto, cierta tendencia de transformación, pero esta no es unánime en todos los indicativos, pues existe respuesta diferencial de estos según su correspondencia con cláusulas expositivas o dispositivas; mayor o menor sensibilidad de las diferentes cláusulas a los condicionantes materiales, y duplicidad de comportamientos por esa ambivalencia. En definitiva, todo parece apuntar a que la mutación afecta más a las formas o "gestos" con los que se expresa la fe, que a sus contenidos. Ni tampoco es simple la posible interpretación de los procesos detectados, en cuanto no se presta la explicación de ese cierto y real cambio a un único sentido. Ello explica que convivan fenómenos aparentemente tan contradictorios como la simplificación del ritual funerario en sus formas externas, la interiorización de la muerte en el seno familiar, e incluso el crecimiento del sentimiento religioso. Pese a lo indicado, curiosamente sí se detecta en la historiografía tanatológica hispana cierto acercamiento a la francesa en otros significativos indicadores, tales como predominio de la edad Moderna como periodo favorito de indagación, sin duda por la atracción de la comentada hipótesis del cambio manifestada y resuelta en aquella etapa, y aplicación de clásicos métodos para la exhumación de documentación notarial, esto es, sondeo, muestreo, muestra aleatoria, cata y cata sistemática o método de "barrido", diversas técnicas con las que poder enfrentarnos a la consabida ingente masa de los protocolos notariales.

Por último, también se observa cierto carácter propio de la producción bibliográfico-tanatológica hispánica por la presencia de dos claras líneas de orientación que traducen su propia evolución.

En este sentido -en realidad la cuestión nuclear-, es claro que dicha evolución ha seguido una doble orientación por la propia dinámica de la investigación, en cuanto aportaciones que iban apareciendo, y la reflexión historiográfica que aquella suscitaba.

La inquietud historiográfica por la muerte despierta en España tras conocerse la ya consabida obra de Vovelle, Piété baroque, de cuya aportación vivimos gran parte de los años ochenta del pasado siglo. Se necesitó, empero, tiempo y esfuerzo para que arraigara en España la atracción por la investigación de la muerte y de otras parcelas de las mentalidades colectivas, hasta el punto de que aún a principios de aquella década se señalaba la conveniencia de que se acometieran en el solar hispánico trabajos de sociología religiosa con métodos cuantitativos asentados documentalmente en libros parroquiales y protocolos notariales, que abrieran camino a una demografía religiosa y a una visión conjunta de las distintas actitudes personales, familiares y sociales que convivieron en la España Moderna (Batllori, 1983, p. 294).

El descubrimiento tuvo lugar en Santiago de Compostela, en torno al núcleo de colaboradores de Eiras, y la publicación de las actas de las ya mencionadas I Jornadas de Metodología Aplicada, supusieron el estreno en España de la nueva tendencia, hecho que inició una primera etapa o andadura. Al grupo gallego se unieron posteriormente el asturiano, catalán, levantino, castellano y el andaluz. Aunque con ciertas diferencias -en 
general, ha predominado el XVIII, el medio urbano y las notariales-, la mayor parte de estos investigadores convergían en el estudio de la muerte movidos por el deseo de alcanzar el único objetivo que daba sentido a esta primera fase. Esto es, verificar si el gran hallazgo de Vovelle para explicar el cambio de actitudes ante la muerte en la crisis finisecular del Antiguo Régimen, es decir, su controvertida conclusión sobre la descristianización de la Provenza en el setecientos, proceso que se detecta y gesta antes de la Revolución, aunque a esta correspondiera su consumación, se cumplía también en España; o si, por el contrario, el solar hispánico mantenía frente a esa transformación un comportamiento propio y diferenciado del francés por su menor radicalidad y mayor tardanza en manifestarse, como así, precisamente con estos últimos caracteres o tintes, después se confirmaría. Los inicios adquieren solidez con la celebración del también ya citado II Coloquio de Metodología Histórica, en 1982. Y a esta fase, que situamos hasta 1985, corresponden los trabajos sobre la temática tanatológica y sobre su religiosidad, desde Barreiro Mallón a Pascua Sánchez o nosotros mismos (Gómez Navarro, 1998b, pp. 19-22, 161-174).

A partir de 1986, la edición de monografías basadas en trabajos de doctorado, sólidas en aparato documental y rigor metodológico, amplían paulatina y progresivamente el ya por entonces sustancioso panorama. Por último, las reuniones científicas de los últimos años -conclusión de los ochenta del pasado siglo y hasta el presente-, revisando resultados ya obtenidos -o aun a veces prosiguiéndolos-, han depurado, aquilatado, apuntado y aplicado nuevos horizontes e instrumentos metodológicos e interpretativos, siendo este, a nuestro entender, el principal bagaje de la segunda época o andadura de nuestra historiografía tanatológica que así y ahí se inicia.

En efecto, la producción historiográfica hispana del último quinquenio de los años ochenta y hasta prácticamente hoy ha obrado, a nuestro parecer, en tres frentes: Por un lado, ha usado del esquema francés aquellos factores que se mostraron útiles en la modulación de comportamientos y que menos recelos despertaron. Nos referimos a la integración de variables físicas - medio rural y urbano- y humanas (sexo, adscripción socioeconómica, nivel cultural, como las principales), por su participación e influencia en la creación y manifestación diferencial de conductas, en el análisis de los contenidos de aquellas cláusulas testamentarias más sensibles a su peso.

Por otro lado, igualmente ha apostado por la defensa de nuestro peculiar carácter ante el cambio, suscrito asimismo por la mayoría de los investigadores hispanos y con el que ya nuestra historiografía se asocia e identifica. Si hay una aportación que hoy le sea genuinamente específica y día a día consolidada por el paso del tiempo y la acumulación de la investigación, tal es aquella; esto es, la diferente posición de España en el cambio de actitudes ante la muerte que se observa en la crisis del Antiguo Régimen; distinción que se basa sobre todo en su consabidas menor radicalidad y demora en revelar algunos, que no todos, sus rasgos. De ahí que ni la cronología ni la rotulación de Vovelle (1760-1790, desbandada, decaimiento de actitudes seculares, consumación del proceso de descristianización) o Chaunu (desde 1720, quiebra del sistema tradicional y aparición de las facetas de modificación, que denomina desocialización de la muerte) pueden aplicarse en puridad, y como han demostrado suficientemente las investigaciones españolas que partían de la percepción del cambio como hipótesis y terminaban a comienzos del ochocientos, al balance de las cláusulas testamentarias más aptas para la definición de dicho cambio. Los estudios realizados hasta ahora en España arrojan resultados sensiblemente diferentes a los franceses. Basta decir, asumiéndolos, que llegamos a 1800, por poner una frontera bien conocida y definida, sin que registremos síntomas alarmantes de la descristianización o laicización francesas, al menos, insisto, de forma absoluta, es decir, en aquellos aspectos y temas en que cifran los respectivos autores franceses esa mutación, y en los tests más expresivos del cambio. Esta observación se completa con otra también bastante nítida: al filo también del ochocientos, y seguramente como trasunto de motivaciones económicas, sociales o culturales, pero no irreligiosas o de descreimiento, se aprecia comportamiento diferencial en la evolución seguida por el mensaje testamentario. A saber: aumento incluso de sinceridad en la expresión religiosa del preámbulo, mas también cierta, aunque paulatina, pérdida de interés por explicitar los contenidos de pronunciamiento más personal o de voluntad 
individual, como son, básicamente, mortaja, cortejo fúnebre, sepultura, misas y legados píos libres, o por reducir su magnificencia. Dicho de otra manera: permanencia del sentimiento religioso ante la muerte y/o su interiorización, en sus decisiones finales, al seno de la unidad familiar o de particulares, combinada, sin embargo, con ciertas modificaciones cualitativas tendentes a la simplificación del ritual o decaimiento de la práctica externa.

Finalmente, la historiografía hispánica también ha decidido incorporar méritos que ampliaban la exploración o indagación sobre la muerte y se producían igualmente al otro lado de los Pirineos. En este sentido, ha seguido con especial atención el consabido particular esfuerzo de profundización del mismo Vovelle, aplicando su modelo interpretativo a los esquemas metodológicos de nuestra más reciente investigación sobre la muerte, y realizando en especial tres tareas:

1. Contraste, cruce y complementariedad de fuentes -las notariales se han acompañado de parroquiales, literarias, artísticas o epigráficas-.

2. Planteamiento de interrogantes desde la horizontalidad y verticalidad de la muerte, peso del tiempo y combinación de distintos planos - muerte sufrida, pensada, vivida-, respectivamente; por eso se ha prestado atención a momentos, en principio, singularmente significativos en la definición de actitudes ante la muerte como terremotos, epidemias, predicaciones, etc., y se ha tratado de conocer la existencia o no de relación entre los distintos espesores de la muerte y, en caso afirmativo, cuál es su naturaleza y manifestaciones; seguir sus contactos; comprender y explicar la difusión de ideas-fuerza en el cuerpo social, y sobre todo comprender sus imbricaciones.

3. La ya mencionada integración de elementos diferenciales -factores geográficos y humanos, en combinación con las cláusulas decisorias de pronunciamiento personal, siempre las más sensibles a su contraste- en una interpretación de conjunto.

A esta segunda etapa o andadura de la historiografía tanatológica hispánica y su religiosidad, más rica y versátil, y desde los años noventa del pasado siglo hasta prácticamente el presente, corresponden tres tipos de productos. Por un lado, monografías de la muerte y su religiosidad propiamente dicha -y, en verdad, las específicas y decisorias-, desde Aranda Mendíaz a Vaquero Iglesias, o Varela. Por otro lado, obras de otra índole entre cuyos contenidos consta un capítulo dedicado casi siempre a las actitudes colectivas ante la muerte -de Maruri Villanueva a Santillana Pérez-. Por último, un conjunto muy generoso de trabajos, variados, dispersos y diversos en temática, extensión, naturaleza y enfoque, y que abordan distintas facetas de la muerte, como comportamientos y actitudes ante la misma por parte de diferentes colectivos sociales urbanos o rurales; respuestas ante la muerte e individualidades; muerte y predicación; muerte y discurso eclesiástico; determinados aspectos del ritual fúnebre; gasto funerario; reflexión sobre el concepto de cambio en la historia de la muerte; clásico estudio del mensaje testamentario en sus cláusulas declaratorias y decisorias; testamento como indicativo de "buena muerte" o abandono de ese carácter; valor y representatividad del testamento como documento; muerte y exploración de fuentes nuevas; muerte física; relación entre muerte y sistema de creencias; muerte y conflicto; o muerte y asociacionismo religioso (Gómez Navarro, 1998b, pp. 24-25, 161-174).

\section{3.- LA DOCUMENTACIÓN NOTARIAL PARA LAS ACTITUDES COLECTIVAS ANTE LA MUERTE: DE LAS ESCRITURAS DE FUNDACIÓN A LAS DE DIVISIÓN Y ADJUDICACIÓN DE BIENES POST MORTEM}

Por ser las escrituras más voluminosas y utilizadas para conocer las actitudes colectivas ante la muerte en la Europa católica debemos comenzar por las actas de última de última voluntad -en concreto, testamentos, y en sus varias y diversas clases, y también codicilos, memoriales y memorias testamentarias-, para seguir 
después con las de división y adjudicación de bienes por ser frecuente complemento de las primeras, y terminar con las más minoritarias, las de donaciones y fundaciones como actas notariales sueltas propiamente dichas.

En efecto, desde el punto de vista tánato-religioso, y por su utilidad, es evidente que con el testamento nos hallamos ante el "documento estrella" con el que la historia de las mentalidades ante la muerte -historia cultural- ha abordado el estudio de este radical, ese instrumento escribanil del que su descubridor para ese empleo seriadamente dijo que es la "confesión de otro tiempo (...), medio de trampear con el silencio de quienes no pueden expresarse por sí mismos” (Vovelle, 1978, p. 9), y que otros han definido como testimonio escrito que entrega una "ritualización de las últimas voluntades" (Lemaitre, 1979, p. 279).

Pese a sus defectos, el testamento sigue siendo fuente muy idónea para el estudio de las actitudes colectivas ante la muerte. Pues, desde el preámbulo al escatocolo, las cláusulas espirituales y patrimoniales, de índole transcendente y material, declaratorias o expositivas -las religiosas del preámbulo, desde la invocación a la encomendación-y decisorias o dispositivas - las religiosas de elección o pronunciamiento personal (mortaja, acompañamiento fúnebre, sepultura, misas y legados píos forzosos y libres, básicamente) y las meramente terrenales de carácter económico o social-, denominación cambiante según autores, del testamento espiritual, como gusta llamarlo Vovelle, conforman una tupida red de elementos explotables, ya aislada o separadamente -aunque no es afortunada ni conveniente su desmembración porque el testamento es documento que "forma un todo, posee una unidad fundamental" (Chiffoleau, 1980, p. 33)-, ya en su correlación, donde los gestos de la práctica traducen de alguna forma las creencias en el más allá, y que se convierten en otros tantos aspectos de los comportamientos colectivos ante la muerte (Vovelle, 1978, pp. 27-28; 1984, pp. 11, 20; 1985, p. 34. Vogler, 1979, pp. 328-330). Para el conocimiento del sentimiento religioso, las idóneas son las más formularias del preámbulo; para el acercamiento a los comportamientos, los personales o más particulares actos de solicitud de las decisorias de contenido espiritual -mortaja, cortejo fúnebre, sepultura, misas, legados-, información conjunta que articula un sistema elaborado de muerte -en realidad, toda una representación mental de la misma-, y ante cuyo mensaje el historiador plantea sus propios interrogantes sobre el peso de cada indicativo y la contribución de los distintos factores diferenciales -sexo, adscripción socioprofesional, nivel cultural, tiempo y medio (rural y urbano) - en la modulación de conductas (Vovelle, 1984, pp. 19-20; Gómez Navarro, 1998a).

Sobre estos rendimientos y servicios, también, sin embargo, cierta cartografía diferencial. En este caso, excepciones, y, una vez más, cumplidoras de su función al confirmar la regla, pues el testamento alsaciano del XVIII, por ejemplo, es un acta esencialmente profana, destinada a asegurar la subsistencia del cónyuge, regular la sucesión de los bienes y evitar conflictos entre los herederos, y en cuya conformación el elemento religioso juega papel muy secundario como prueba la escasa proporción del discurso espiritual en el conjunto de su contenido y la muy modesta, casi simbólica, inversión en el cielo en forma de misas, circunstancias ambas que lo hacen poco apto para estudios de carácter religioso (Vogler, 1979, pp. 317-330). Igualmente, cabe decir del instrumento de última voluntad otorgado para casi la misma época en la Baja Austria, documento esencialmente jurídico, empleado como vehículo de expresión del luteranismo y, por tanto, no dictado con fines espirituales -ausencia, por ejemplo, de la solicitud de misas, pero, curiosamente, presencia de la práctica de la caridad por la dejación de legados piadosos, sobre todo entre los italianos católicos de Viena-, lo que le convierte asimismo en muy poco dúctil como revelador habitualmente entendido en la historia de las mentalidades de la muerte y su religiosidad (Berenger, 1979).

Ya sabemos que también la historiografía modernista hispana ha reconocido esta valía y los trabajos publicados en España centrados en esta parcela de la investigación histórica no solo lo han empleado sistemáticamente como material básico al estimarlo "fuente predilecta para el estudio de la evolución de las mentalidades colectivas, principalmente en el aspecto religioso y de la desacralización del mundo moderno, a través de su análisis serial y masivo" (Eiras Roel, 1980, p. 18), sino que en los últimos tiempos se ha sumado asimismo a los saludables esfuerzos por acercarse a esta fuente con la consabida lógica prevención -papel del formulario y del notario como intermediario en la transmisión escrita de una voluntad verbalmente expresada 
(su veracidad); representatividad social; y necesidad de contrastarla con otras huellas (su suficiencia), singularmente cuando también en algún caso hispánico se ha detectado cierto vaciado de contenido religioso que lo hace frágil en este uso (García Cárcel, 1984, pp. 123-124)-, que hoy sabemos exige su manipulación (Vovelle, 1984, p. 19; 1985, pp. 25-36). En este sentido, la consabida incorporación en las aportaciones hispanas más recientes de esta parcela histórica de los elementos moduladores de conductas -espacio, tiempo y factores sociales diferenciadores- y del planteamiento de ciertas cuestiones que se convierten en clásica problemática de los estudios sobre la muerte -relación entre los distintos niveles de la muerte, influjo de los discursos en los gestos, imbricación norma/actuación, y aun influjo de medidas culturales y políticas-, $\mathrm{y}$, por tanto, de las tendencias que integran la más pura renovación metodológica en este tema y ante él han hecho madurar la historiografía tanatológica española; si bien es aún escaso el uso de las escrituras de última voluntad en otras etapas históricas -sobre todo con aprovechamiento masivo y seriado y pese a sus enormes potencialidades también al efecto- o para el medio rural, salvo muy honrosas excepciones entre las que me hallo, porque lo indagué en dos representantes significativos de la sierra y campiña cordobesas, como son Fuente Obejuna y Montilla, respectivamente. Pero, con ser todo ello importante, no lo es menos el hecho de que nos encontramos ante un instrumento notarial versátil en cuanto a que su factura, formal y de fondo, responde, al menos, a cinco tipologías diferentes, según he constatado en mis investigaciones sobre el medio rural y urbano cordobés del Antiguo Régimen en sus 4.569 instrumentos notariales de última voluntad.

Esto es -y según la representación de su volumen-, los testamentos pueden ser, en efecto, individuales, mancomunados, de o por poder, por abintestatos, y cerrados, todos ellos presentes en el medio urbano y rural cordobés, salvo los testamentos por abintestatos, de los que no consta ninguna escritura en Fuente Obejuna. Cinco clases de testamentos que pueden sintetizarse, en realidad, en dos grandes grupos según criterios de carácter formal, o jurídico. Por los primeros, hablamos de documento abierto o nuncupativo, dictado verbalmente ante notario y cumplido número de testigos -es lo que significa "nuncupativo"- e integrado por las cuatro primeras tipologías indicadas, es decir, individuales, mancomunados, de o por poder, y por abintestatos; o de documento cerrado, sellado y lacrado, entregado al notario en presencia de siete testigos y cuyo contenido solo conoce el otorgante o su redactor, y constituido precisamente por su homónimo en la muestra documental que conozco y he investigado. Las motivaciones jurídicas se desglosan, a su vez, en número de protagonistas en su dictado - uno, testamento individual; más de uno, testamentos conjuntos o mancomunados, por ejemplo-, y grado de participación del otorgante o del destinatario en su ejecución, en cuya última circunstancia siempre aparecerá más de un nombre -verbigracia, los testamentos de o por poder, o por abintestatos- (López Fando, 1798, pp. 17-18, 30-36, 47-59, 71-72. Arce y Cervantes, 1981, p. 542. Gomez Navarro, 1996, pp. 10-29; 1998b, pp. 37-47). Por razones de espacio, veamos con algún detalle las dos últimas tipologías, por su peculiaridad y por hallarlas en los protocolos cordobeses rurales y urbanos indagados.

En cuanto a los testamentos por abintestatos, denominados así por responder al que reciben los feligreses, una vez fallecidos, por parte de su párroco, ofrecen la oportunidad de observar el grado de cumplimiento y desarrollo a posteriori de una voluntad casi siempre muy poco definida o bastante inconcreta, especialmente en las cláusulas decisorias, expresada a priori. Se legitiman en las facultades que las Constituciones Sinodales del Obispado de Córdoba conceden a vicarios y rectores para que, de común acuerdo con familia y herederos, inviertan por el alma del difunto lo que su hacienda y "costumbre del lugar" permitan gastar, y después den forma a esa distribución “ante Notario ó Escribano para su mayor validación” (Gómez Navarro, 1998b, pp. 39-41); por lo que, en realidad, las Sinodales legislan en lo que directamente les compete, esto es, la salvación de un alma intestada que muere sin el auxilio espiritual que es el testamento, casi un octavo sacramento en la cosmovisión y religiosidad postridentina de la muerte (Gómez Navarro, 2016a). En todo caso, este tipo de acta notarial testamentaria toca la fundamentación jurídica del testamento, cuya ejecución descansa en la libertad del individuo para invertir en pro de su alma sobre la quinta parte de sus bienes, llamada también, precisamente por ello, "quinto del alma", "cuota pro ánima” o "quinto de libre disposición" (Maldonado 
y Fernández del Torco, 1944, pp. 73-75). Desembocamos también así en el gran peligro que conllevaba la acción de esta gestión: la posible manipulación de la conciencia del moribundo $-\mathrm{o}$, en su defecto, de la de su propia familia- para la obtención de un determinado capital invertido en la salvación del alma y no siempre allegado por métodos muy ortodoxos -o tal vez desviado de la satisfacción de otras necesidades puramente materiales, si se quiere-, pero no por eso menos reales. Como es fácil suponer, la dimensión de esta actuación, posible también en los sujetos de otros tipos testamentarios, afecta más directamente a los intestados, ya que, por su propia naturaleza -ausencia de una voluntad declarada expresa y personalmente por el interesado-, esta clase de documento se muestra especialmente vulnerable y permite mayor margen de maniobra en aquel sentido por parte del clérigo que otorgue testamento ante notario o de aquellos en quienes recayere, en última instancia, la responsabilidad -y hasta cierto punto la tranquilidad- de poder encargar por el deudo abintestato unas misas, aun cuando no medie protocolización. Por ello, quizás la acumulación en un determinado momento de una serie de casos que demostraban la extralimitación de esa gestión explique la adopción de ciertas medidas por la administración ilustrada encaminadas a prohibir el ejercicio secular de dicha intervención, modificar la conducta popular -bastante proclive por lo demás a seguir apoyándola con su propia respuesta favorable-, y corregir ciertos desmanes cometidos impunemente al amparo de esa función (Gómez Navarro, 2016b, 477-487).

Por su parte, los testamentos cerrados, ológrafos y alógrafos, denominados también inscriptis, misticos o solemnes, deben la distinción de su título a la posibilidad de que otorgante y redactor no coincidan en la misma persona. La redacción de este tipo de escritura de última voluntad no es pública -es decir, ante escribano- sino privada; el notario es mero guardián de su oculto contenido, que no se conocerá hasta que por muerte del afectado y tras las oportunas diligencias de reconocimiento por parte de los testigos estantes en el momento de su depósito o quienes les representen, se proceda a su apertura con todas las garantías jurídicas previstas por la ley. La diferencia de ser ológrafo o alógrafo estriba en que el primero es redactado directa y personalmente por el otorgante, de su puño y letra, y solo él conoce su tenor; en tanto que el segundo no es redactado ni directa ni personalmente por el otorgante debido a la concurrencia de cualquier impedimento, pero la ley garantiza y permite que lo haga por él otra persona de su completa confianza, que accede sin coacción a cumplirle dicha función. Pese a su muy exigua magnitud, notarial o escriturariamente, son importantes porque confirman precisamente el aplastante peso del testamento abierto como documento preferido del testador cordobés - rural y urbano- y, por extensión, meridional, como asimismo sucede en otras latitudes hispánicas peninsulares; porque su participación sirve como recurso metodológico de contrapunto al formulario escribanil del nuncupativo, aunque no suele haber sorpresas, pues la elaboración de sus cláusulas participa de una misma mentalidad común, o, si se quiere -y como se ha señalado-, la pluma de los notarios no es la que estereotipa las fórmulas (Chaunu, 1978, pp. 222, 231-232); y porque su contribución podría reflejar la introducción del elemento diferenciador que es el nivel cultural (Vovelle, 1979, p. 264). En medio de una sociedad mayoritariamente iletrada que debe acudir al notario para la expresión escrita de sus últimas voluntades, el hecho de que a lo largo de más de cien años tan solo trece cordobeses -once en la capital, y uno por cada uno de sendos representantes del medio rural de Montilla y Fuenteobejuna: una propietaria, vinculada socialmente a importante familia de labradores locales y soltera; y un clérigo de lugar, respectivamente- fueran capaces de redactar con corrección y por sí mismos las suyas -solo, pues, unos pocos; en realidad muy pocos-, y dos más se limitaran a signarlas con una cruz por no saber firmar, es, en efecto, la mejor prueba de que nos hallamos ante una sociedad aún muy lejos de alcanzar deseables niveles de alfabetización y, por tanto, muy alejada de la cultura escrituraria y libresca, o, lo que es aún peor, dependiente de los estrechos e influyentes círculos que la controlan.

De última voluntad son también escrituras como codicilos, memoriales y memorias testamentarias. Por lo general muy breves, se utilizan comúnmente para cambiar, añadir o suprimir alguna cláusula o cláusulas de testamento, sin tener que recurrir a una nueva dación de este. 
Las escrituras de división y adjudicación de bienes con motivo de la muerte -esto es, partijas, particiones e inventarios post mortem-, pese a su conocida reducción y su corta presencia en relación al instrumento testamentario -3\% en el caso de todo el ámbito, rural y urbano, cordobés-, quizás por escasa difusión y carácter opcional de este documento entre la población; extensión de ciertas costumbres locales que se inclinan por la liquidación de los bienes privadamente sin intervención del notario y, por ende, protocolización del balance final (Daumard, 1962, p. 144. Garden, 1975, p. 155. Álvarez Santaló-García Baquero, 1980, p. 132); razones económicas, porque "por los cortos bienes que quedaron no se hizo inventario de ellos", o como "no debo nada a nadie, mando que no se haga inventario de mis bienes"; o a todas o parte de esas motivaciones (Gómez Navarro, 1998b, pp. 49-50), es obvio que para estudios sobre la muerte resultan indispensables por cuanto gran parte del contenido y aplicación de su rica información son eminentemente funerarias. Sin olvidar el amplio beneficio que asimismo reportan para distintos ámbitos del saber histórico, también en cierta medida relacionados o vinculados con lo funerario-religioso, como el plano económico -útiles, medidas, capacidades, bienes inmuebles, movientes y semovientes, herramientas, especies-, de cultura material -ajuar, mobiliario, joyas, vestidos...-, nivel cultural -bibliotecas-, e incluso de arqueología industrial, con la descripción y distribución del espacio vital que es la misma casa. De tal forma que, de su mano, el escribano se convierte en cineasta del pasado porque reproduce, por lo general con bastante fidelidad, detallismo y minuciosidad, el espíritu de toda una época; conducidos de su mano podemos entrar sin miedo en este especial "túnel del tiempo" que son las condiciones económicas, sociales, culturales y mentales de la gente corriente por ella recreadas. Ahora bien, su empleo también exige precauciones. Esta escritura necesita asimismo su depuración y no solo por la diferente atención con que cada notario anota o suma los datos, sino sobre todo porque los inventarios post mortem, por sus propias peculiaridades y al menos en algunos de sus contenidos y mensajes, resisten la serialización y homogeneización al responder de alguna forma a la costumbre local de quienes los realizan, característica comprobada al comparar este instrumento público entre los tres ámbitos geográficos cordobeses analizados.

A efectos funerario-piadosos, tres rendimientos son especialmente interesantes:

De carácter religioso y cultural: escrituras de división de bienes que aportaban cuadros, urnas, estampas, imágenes y sobre todo bibliotecas, fijándonos especialmente en los libros de contenido religioso y singularmente funerario.

De índole económica: valoración total del cuerpo de hacienda; gastos de derechos parroquiales; coste global por funeración; participación de aquéllos en ésta; evaluación y representación de todos los gastos realizados y causados por la muerte en el primer concepto.

Información cualitativa: distintos capítulos del gasto fúnebre que permiten en ocasiones reconstruir paso a paso el ritual que no queda explicitado en el documento de última voluntad o cuyo otorgante lo relega a la decisión de terceros. Apartados como el de "fe de muerte", muy rico, útil y casi exclusivo preámbulo del inventario post mortem urbano cordobés para conocer la presentación del cadáver tras la misma expiración; gastos por enfermedad y asistencia de eclesiásticos; o datos sobre caja, túmulo, velatorio, lutos, etc., hallan su debido acomodo y permiten rellenar con cierta comodidad el muy frecuente silencio del testamento sobre esos y otros puntos del ceremonial funerario.

Advertimos, sin embargo, que, según el nivel diferencial de información de cada inventario post mortem, en esa misma medida su empleo puede ser también variable (Bennassar, 1984, pp. 139-141).

Por último, escrituras notariales de donaciones y fundaciones como tales dos documentos públicos sueltos e independientes, al margen, pues, del testamento.

Unidas por el denominador común de su fundamentación religiosa y aplicación, y ambas breves pues solo incluyen, casi en este mismo orden, invocación o encabezamiento, fecha, identificación del otorgante -donante o fundador- y del destinatario -cenobios, parroquias, ermitas, asociaciones religiosas...-, objeto de la donación o fundación, cuantía, condiciones, y obligaciones de firmeza en el cumplimiento, estas dos 
actas escribaniles permiten realizar algún gesto en favor del alma. Dicho de otra forma: por lo general toda donación conlleva fundación y viceversa, pues ambas escrituras notariales pertenecen al conjunto de instrumentos de "causa pía", esto es, "toda obra realizada principalmente para gloria de Dios, por amor al prójimo y el bien del alma” (Rubio Rodríguez, 1976, pp. 9-10; Liva, 1979, p. 97). Por ello se suman a todo el conjunto ya explicitado con el que la sociedad católica del Antiguo Régimen hispana y europea, rural y urbana, encaró durante mucho tiempo su destino final y la "memoria de si”", y el historiador hoy puede conocerlo.

\section{REFERENCIAS}

Álvarez Santaló, L. C., García-Baquero González, A. (1980). La nobleza titulada en Sevilla, 1700-1834. (Aportación al estudio de sus niveles de vida y fortuna). Historia, Instituciones, Documentos, 7, 125-167.

Arce y Cervantes, J. (1981). Reflexión sobre el testamento. Anales de la Academia Matritense del Notariado, XXII (2º), $531-545$.

Batllori, M. (1983). Algunos problemas abiertos sobre la Iglesia en España durante el siglo XVIII. En II Simposio sobre el Padre Feijoo y su siglo: II (pp. 293-299). Oviedo: Universidad.

Bennassar, B. (1984). Los inventarios post-mortem y la Historia de las Mentalidades. En Actas del II Coloquio de Metodología Histórica Aplicada: La Documentación Notarial y la Historia: II (pp. 139-146). Santiago de Compostela: Universidad.

Berenger, J. (1979). Les testaments du maréchal de Basse Autriche. En B. Vogler (Comp.), Les Actes Notariés. Source de l'Histoire Sociale XVIe-XIXe siècles (pp. 291-303). Strasbourg: Istra.

Burguière, A. (Dir.). (1986). Dictionnaire des Sciences Historiques. París: PUF.

Calleja-Puerta, M., Domínguez-Guerrero, Ma L. (Eds.). (2018). Escritura, notariado y espacio urbano en la corona de Castilla y Portugal (siglos XII-XVII). Gijón: Ediciones Trea.

Carbonnell, CH.-O. (1986). La Historiografía. Méjico: FCE.

Cardoso, C. F. S., Pérez Brignoli, H. (1986). Los Métodos de la Historia. Introducción a los problemas, métodos y técnicas de la historia demográfica, económica y social. Barcelona: Crítica.

Chaunu, P. (1978). La mort à Paris XVIe, XVIIe et XVIIIe siècles. París: Fayard.

Chiffoleau, J. (1980). La comptabilité de l'au delà. Les hommes, la mort et la religion dans la région d'Avignon à la fin du Moyen Age (vers 1320-vers 1480). París: École Française de Rome.

Daumard, A. (1962). Structures sociales et classement socio-professionnel. L'apport des archives notariales au XVIIIe et au XIXe siècle. Revue Historique, 461, 139-154.

Domínguez-Guerrero, Mª L. (2019). Las escribanias públicas del alfoz de Sevilla en el reinado de Felipe II. Sevilla: Universidad.

Eiras Roel, A. (1985). De las fuentes notariales a la historia serial: una aproximación metodológica, Aproximación a la Investigación Histórica a través de la Documentación Notarial. Cuadernos de Seminario "Floridablanca", 1, 15-30.

Eiras Roel, A. (1984). La metodología de la investigación histórica sobre documentación notarial: para un estado de la cuestión. Introducción General. En Actas del II Coloquio de Metodologia Histórica Aplicada. La Documentación Notarial y la Historia: I (pp. 13-30). Santiago de Compostela: Universidad.

Eiras Roel, A. (1981). Tipología documental de los protocolos gallegos. En La Historia Social de Galicia en sus fuentes de protocolos (pp. 9-17, 21-113). Santiago de Compostela: Universidad.

Eiras Roel, A. (1980), La Documentación de Protocolos Notariales en la Reciente Historiografía Modernista, Estudis Histórics i Documents dels Arxius de Protocols, VIII, 7-27.

Extremera Extremera, M. A. (2009), El notariado en la España Moderna. Los escribanos públicos de Córdoba (siglos XVI-XIX), Madrid: Calambur.

Extremera Extremera, M. A. (2001), Los escribanos de Castilla en la Edad Moderna. Nuevas líneas de investigación, Chronica Nova, 28, 159-184. 
Febvre, L., (1953) [1986] Combates por la Historia, Barcelona: Planeta.

Franco Rubio, G. (2018), El ámbito doméstico en el Antiguo Régimen. De puertas adentro, Madrid: Editorial Síntesis.

García Cárcel, R. (1984), "La muerte en la Barcelona del Antiguo Régimen. (Aproximación Metodológica)”. En Actas del II Coloquio de Metodología Histórica Aplicada. La Documentación Notarialy la Historia, II, 115-124, Santiago de Compostela: Universidad.

García Fernández, M. (1995). Tendencias historiográficas recientes sobre religiosidad popular e historia de la muerte y de las mentalidades. En Barros, C. (Ed.), Historia a Debate, II: Retorno del Sujeto (pp.143-157). La Coruña: Universidad.

García Martínez, C. (2016). Vivir y morir en la Baeza moderna (1550-1650). Jaén: Universidad.

Garden, M. (1975). Lyon et le lyonnais au XVIIIe siècle. París: Flammarion.

Gittings, C. (1988). Death, burial and the individual in Early Modern England. London: Routledge.

Gómez Navarro, Ma S. (2016a). Reforma y renovación católicas. Siglos XVI-XVII. Madrid: Editorial Síntesis.

Gómez Navarro, $M^{a}$ S. (2016b). Estado e Iglesia también ante las conciencias: el regalismo se impone a las voluntades (Córdoba, 1750-1800). En Campos y Fernández de Sevilla, J. (Coord.), Las dos ciudades. Relaciones IglesiaEstado (pp. 473-488). El Escorial: Instituto Escurialense de Investigaciones Históricas y Artísticas.

Gómez Navarro, Ma S. (2003). Documentación notarial e historia: Luces y sombras de una relación inexcusable. En Espino Jiménez, F. M. (Ed.), Actas de las V Jornadas sobre Historia de Montilla (pp. 37-75). Montilla: Ayuntamiento.

Gómez Navarro, Ma S. (1998a). Una elaboración cultural de la experiencia del morir. Córdoba y su provincia en el Antiguo Régimen. Córdoba: Universidad.

Gómez Navarro, Ma S. (1998b). Materiales para la experiencia del morir en la Córdoba del Antiguo Régimen. Historiografía, Heuristica, Metodología. Córdoba: Universidad.

Gómez Navarro, Mª S. (1996). La muerte en la provincia de Córdoba. Inventario de escrituras notariales de Córdoba, Montilla y Fuente Obejuna (1650-1833). Sevilla: Ilustre Colegio Notarial.

González de Amezúa y Mayo, A. (1951). Apuntes sobre la vida escribanil en los siglos XVI al XVIII. En Opúsculos Histórico-Literarios: III (pp. 279-307). Madrid: CSIC.

Gorer, G. (1955). The Pornography of Death. Encounter, $49-52$.

Laffont, J-L. (Dir.). (1992). Visages du notariat dans l'histoire du Midi toulousain XIVe-XIXe siècles. Toulouse: Presses Universitaires du Mirail.

Laffont, J-L. (Dir.). (1991). Problèmes et méthodes d'analyse historique de l'activité notariale (XVe-XIXe siècles). Toulouse: Presses Universitaires du Mirail.

Lemaitre, A. J. (1979). Histoire d'une marginalité: les testaments bretons aux XVIIIe-XIXe siècles (1750-1850). En Vogler, B. (Comp.), Les Actes Notariés. Source de l'Histoire Sociale XVIe-XIXe siècles (pp. 279-289). Strasbourg: Istra.

Liva, A. (1979). Notariato e documento notariale a Milano. Dall'Alto Medioevo alla fine del Settecento. Roma: Consiglio Nazionale del Notariato.

López Fando, J. M. (1798). Prontuario de Testamentos y Contratos: I. Madrid: Imprenta de D. Benito Cano.

López López, R. J. (1988). El uso del testamento en la ciudad de Oviedo, 1650-1840. Revista de Derecho Notarial, 139, 95-124.

Madariaga Orbea, J. (1989). Thánatos en el archivo. Consideraciones sobre la investigación histórica de las actitudes ante la muerte. La(s) Otra(s) Historia(s). (Una reflexión sobre los métodos y los temas de la investigación histórica), 2, 79-108.

Maldonado y Fernández del Torco, J. (1944). Herencias en favor del alma en el derecho español. Madrid: Revista de Derecho Privado.

Manners, J. M. (1981). Death and the Enlightenment. Changing Attitudes to Death among christians and Unbelievers in Eighteenth Century in France. Oxford: Paperbacks. 
Marcos Martín, A. (1989). Religión 'predicada' y religión 'vivida'. Constituciones Sinodales y visitas pastorales: ęun elemento de contraste? En Álvarez Santaló, L. C., Buxó i Rey, Ma J., Rodríguez Becerra, S. (Coords.), La Religiosidad Popular, II: Vida y muerte: La imaginación religiosa (pp. 46-56). Barcelona: Anthropos.

Martínez Gil, F. (1993). Actitudes ante la muerte e Historia Social en la España Moderna. Historia Social, 16, 19-32.

Mateo Bretos, L. (1994). La historiografía de la muerte: Trayectoria y nuevos horizontes. Manuscrits, 12, 321-356.

Mendoza García, E. Ma (2007a). Los escribanos de Málaga en el reinado de Felipe IV (1621-1665). Málaga: Diputación.

Mendoza García, E. Ma (2007b). Pluma, tintero y papel. Los escribanos de Málaga en el siglo XVII (1598-1700). Málaga: Universidad.

Moreno Trujillo, A. (1988). 1569: Un año en la vida de Huelma a través de su notaría. Granada: Ilustre Colegio Notarial.

Meyer, J. (1979). La documentation notariale en Bretagne à l'époque moderne. En Vogler, B. (Comp.), Les Actes Notariés. Source de l'Histoire Sociale XVIe-XIXe siècles (pp. 31-45). Strasbourg: Istra.

Pérez del Río, E. G. (1984). La muerte como vocación en el hombre y en la literatura. Barcelona: Laia.

Pérez García, J. M. (1975). Los Protocolos Notariales de Pontevedra: Algunas posibilidades metodológicas en el campo de la historia rural. En Actas de las I Jornadas de Metodología Aplicada de las Ciencias Históricas: V: Paleografía y Archivistica (pp. 291-304). Santiago de Compostela: Universidad.

Poisson, J. P. (1976). L'activité notariale comme indicateur socioéconomique: l'exemple de la Fronde. Annales, 5, 996-1009.

Rubio Rodríguez, J. J. (1976). Las causas pias en los juristas clásicos españoles de los siglos XV al XVII (Estudio históricojurídico). Sevilla: Universidad.

Russo, C. (1976). La storiografía socio-religiosa e i suoi problema. En Russo, C. (A Cura di), Società, Chiesa e Vita Religiosa nell'Ancien Régime (pp. xiii-ccxliv). Napoli: Guida editori.

Topolski, J. (1982). Metodología de la Historia. Madrid: Cátedra.

Viguerie, J. de (1985). Historia religiosa. En Floristán Imízcoz, A., Olábarri Gortázar, I., Vázquez de Prada Vallejo, V. (Coords.), La Historiografia en Occidente desde 1945. Actitudes, Tendencias y Problemas Metodológicos. Actas de las III Conversaciones Internacionales de Historia (pp. 189-208). Pamplona: Eunsa.

Vogler, B (Comp.). (1979). Les Actes Notariés. Source de l'Histoire Sociale XVIe-XIXe siècles. Strasbourg: Istra.

Vovelle, M. (1985). Ideologías y Mentalidades. Barcelona: Ariel.

Vovelle, M. (1984). Minutes notariales et histoire des cultures et des mentalités. En Actas del II Coloquio de Metodología Histórica Aplicada. La Documentación Notarialy la Historia: II (pp. 9-26). Santiago de Compostela: Universidad.

Vovelle, M. (1983). La mort et l'Occident. De 1300 à nos jours. París: Gallimard.

Vovelle, M. (1979). Un préalable à toute histoire sérielle: la représentativité sociale du testament (XIVe-XIXe siècle). En Vogler, B. (Comp.), Les Actes Notariés. Source de l'Histoire Sociale XVIe-XIXe siècles (pp. 257-277). Strasbourg: Istra.

Vovelle, M. (1978). Piété baroque et déchristianisation en Provence au XVIIIe siècle. París: Seuil.

\section{Notas}

* Este trabajo se ha realizado en el marco del Proyecto de investigación de I+D+i PID2019-106735GB-C22, del Ministerio de Ciencia e Innovación. 